\title{
Turnike açılma zamanının diz artroplastisi sonrası kan kaybına etkisi
}

\author{
The timing of tourniquet release in total knee arthroplasty and its influence on blood loss \\ Eyüp Çağatay Zengin*, Birol Gülman, Murat Erdoğan, Hicabi Sezgin, Alper Çıraklı, Ahmet Pişkin \\ Ondokuzmayls Üniversitesi Tıp Fakültesi, Ortopedi ve Travmatoloji Anabilim Dalı, Samsun, Türkiye
}

\begin{tabular}{|c|c|}
\hline \multicolumn{2}{|c|}{ MAKALE BİLGİLERİ } \\
\hline \multicolumn{2}{|c|}{ Makale geçmişi } \\
\hline Geliş tarihi & : $01 / 04 / 2012$ \\
\hline Kabul tarihi & $: 14$ / 04 / 2012 \\
\hline
\end{tabular}

\section{* Yazışma Adresi:}

Eyüp Çağatay Zengin

Ondokuzmayıs Üniversitesi Tıp Fakültesi, Ortopedi ve Travmatoloji Anabilim Dalı,

Samsun, Türkiye

E-posta: zengincagatay@hotmail.com

\section{Anahtar Kelimeler: \\ Diz artroplastisi \\ Turnike kullanımı \\ Kanama kontrolü \\ Kanama \\ Kan transfüzyonu \\ Komplikasyon}

\section{Key words:}

Knee artroplasty

Tourniquet use

Hemostasis

Blood drainage

Blood transfusion

Complication

\section{ÖZET}

$\mathrm{Bu}$ çalışma, perioperatif ve postoperatif kanama miktarına, turnike açılma zamanının etkisinin olup olmadığını araştırmak amacıyla yapıldı. Total diz artroplastisi uygulanan, yaşları 52 ile 84 arası, 80 hasta prospektif randomize bir çalışma ile değerlendirildi. Hastalar rastgele iki gruba ayrıldı. Tüm hastalarda, arka çapraz bağın korunduğu bikompartmanal total diz protezi kullanıldı. Grup 1'de, proteze ait komponentler yerleştirildikten sonra turnike açıldı, kanama kontrolü yapıldı. Grup 2'de, cilt kapatılıp kompresif bandaj uygulandıktan sonra tunike açıldı. Birinci gün, hemovak drenlere ortalama kanama miktarı; Grup 1'de $400 \mathrm{ml}( \pm 208,5)$, Grup 2'de $530 \mathrm{ml}( \pm 136,6)$ olarak değerlendirildi $(\mathrm{p}<0,05)$. Perioperatif ve postoperatif ihtiyaç duyulan transfüzyon miktarı ile preoperatif, postoperatif ve taburcu olduğu gün alınan hemoglobin değerleri her iki grupta benzerdi. İntraoperatif turnike açılıp kanama kontrolü yapılmasının total diz artroplastisinde kanamayı azalttı̆̆ fakat transfüzyon ihtiyacını değiştirmediği sonucuna vardik.

J. Exp. Clin. Med., 2012; 29:149-151

\section{ABSTRACT}

We performed a prospective, randomized study to investigate the effect of tourniquet release on the perioperative and postoperative blood loss. Eighty patients with ages ranging 52 to 84 , who received total knee artroplasty were evaluated. Patients were randomly divided in two groups. Posterior cruciate retaining, bicompartmental total knee prostheses were used in all. In group 1, the tourniquet was deflated intraoperatively after the prosthetic componenets were settled and hemostasis was done. In group 2, the tourniquet was released after the wound was closed and a compressive bandage was applied. First day mean blood drainage was $400 \mathrm{ml}( \pm 208.5)$ in group 1 and $530 \mathrm{ml}( \pm 136.6)$ in group 2 $(p<0.05)$. The mean number of perioperative and postoperative blood transfusions given, hemoglobin values were similar in both groups. Intraoperative tourniquet release and hemostasis reduce blood loss but does not reduce blood transfusion.

J. Exp. Clin. Med., 2012; 29:149-151

\section{Giriş}

Total diz artroplastisi (TDP) sonrası kanama miktarını azaltmak için kanama kontrolü pratik uygulamada kullanılmaktadır (Lotke ve ark., 1991). Pnömatik turnike kullanımının kan kaybını azalttığı, cerrahi esnasında daha iyi bir görüş sağladığı ve çimentolamayı kolaylaştırdığg genel olarak kabul görmüş olmasına rağmen, turnike açılma zamanı ve kanama kontrolü yapılıp yapılmaması konusunda ortak bir görüş yoktur. Genikulat arterin koagüle edilmesinin kan kaybını azalttığını öne süren çalışmalar vardır (Page ve ark., 1994). Turnikenin erken açılmasının turnike kullanımına bağlı olası komplikasyonları azalttığını gösteren (Rama ve ark., 2007) ayrıca kanama kontrolü yapılmasının kan kaybı üzerine etkisi olmadığını gösteren çalışmalar da vardır (Hersekli ve ark., 2004). Bizim çalışmamızın amacı; intraoperatif turnike açılması ve kanama kontrolü yapılmasının kan kaybı üzerine etkisini araştırmaktır.

\section{Hastalar ve yöntem}

Ondokuz Mayıs Üniversitesi Etik Kurul onayı ve hasta onam formu alındıktan sonra, primer osteoartrit nedeniyle arka çapraz bağın korunduğu, iki kompartmanlı diz artroplastisi 
uygulanan, bilinen bir kanama hastalığı olmayan, yaşları 52 ile 84 arası değişen 80 hasta çalışmaya alındı. Hastalar rastgele 2 gruba ayrıldı. İmplantlar yerleştirildikten sonra turnikenin açılıp kanama kontrolünün yapıldığı hastalar Grup $1(n=37)$, insizyon kapatılıp kompresif bandaj uygulandıktan sonra turnikenin açıldığı Grup $2(n=43)$ den oluşmaktadır (Tablo 1).

\begin{tabular}{lcc}
\hline \multicolumn{3}{l}{ Tablo 1, Hastaların demografik özellikleri } \\
& $\begin{array}{c}\text { Grup 1 } \\
(\mathrm{n}=37)\end{array}$ & $\begin{array}{c}\text { Grup 2 } \\
(\mathrm{n}=43)\end{array}$ \\
\hline Yaş (yıl) & $63,8 \pm 6,2$ & $66,0 \pm 6,6$ \\
Cinsiyet (E/K) & $5 / 32$ & $8 / 35$ \\
\hline
\end{tabular}

Bütün operasyonlar aynı tecrübeye sahip operatörler tarafından kombine spinal epidural anestezi altında yapıldı. Bütün cerrahlar standart bir cerrahi prosedürü kulland. Turnike 350-400 mmHg'ye kadar şişirildi ve orta hat insizyonu kullanılıp, medial parapatellar artrotomi yapıldı. İki kompartmanlı diz protezi kullanıldı. Hiç bir hastada patellar komponent değiştirilmedi. Patella etrafındaki osteofitik çıkıntılar küret ile temizlenip kenarlarına steril kemik mumu sürüldü. Arka çapraz bağ bütün hastalarda korundu. Kanama kontrolü için elektrokoter kullanıldı. İki adet hemovak dren yerleştirilip, quadriceps tendonu kilitli sütürler ile kapatıldı ve cildi kapatmak için stapler kullanıldı. Postoperatif takiplerde hemoglobin değeri 10'un altında olan hastalara kan transfüzyonu yapıldı. Hastaların preoperatif, postoperatif ve taburcu olurken hemoglobin $(\mathrm{Hb})$ değerleri ölçüldü.

Grup 1'de turnike, implantlar yerleştirildikten sonra açıld1. Batın kompresler ile yaraya beş dakika baskı uygulandı. Kanayan bütün arteryel ve venöz yapılar koagüle edildi. İki adet hemovak dren yerleştirildi ve insizyon kapatıldıktan sonra drenler açıldı.

Grup 2'de turnike, insizyon kapatılıp kompresif jones bandajı yapıldıktan sonra açıldı. Hemovak drenler insizyon kapatıldıktan iki saat sonra açıldı. Her iki grupta hemovak drenler cerrahiyi takiben 48 saat sonra çekildi. Tromboemboli profilaksisi için bütün hastalara düşük molekül ağırlıklı heparin (clexane) kullanıldı. Hastalara cerrahiden $30 \mathrm{dk}$ önce 1 gr sefazolin ile profilaksi yapıldı. Tüm hastalara aynı rehabilitasyon programı uygulandı. İzometrik quadriceps egzersizleri operasyondan hemen sonra başlandi. Operasyondan 48 saat sonra drenler çekilip hastalara diz egzersizleri başlandı ve tam yük vererek yürümelerine izin verildi. Hiçbir hastamızda continuous passive motion (CPM) cihazı kullanılmadı. Hiçbir hastamızın postoperatif rehabilitasyonunda sürekli pasif hareket (CPM) sağlayan cihazlar kullanılmadi.

İki farklı diz protezi seti (Genesis; Simith \& Nephew, Advance; Wright) kullanıld1. Hemoglobin değerleri preoperatif, cerrahiden hemen sonra ve taburcu olurken bakıld1. Bütün hastalarda cerrahi öncesi trombosit sayıs1, PT, PTT ve INR çalışıldı, bu değerlerin normal sınırlarda olduğu görüldü. Kapalı drenaj sistemindeki kan miktarı grupları bilmeyen nöbetçi asistan doktor tarafindan kayıt edildi. Hastaların kan transfüzyon ihtiyacına klinik ve labaratuar değerlerine göre cerrah tarafindan karar verildi. Verilen kan miktarı ünite şeklinde kayıt edildi.

İstatiksel değerlendirmede SPSS for Windows V15,0 (SPSS Inc., Chicago, IL, USA) kullanıldı. Her iki gruptaki verilere Kolmogorov smirnov testi uyguland. Verilerin normal dağılıma uymadığı anlaşıldı, log 10 tabanında dönüşüm uyguland. İki gruptaki verilerin istatiksel değerlendirilmesinde Mann Whitney $U$ testi kullanıldı. Sürekli değişkenler ortalama \pm standart sapma (SD) ve ortanca (minimum ve maksimum) olarak ifade edildi. P değerinin 0,05 den küçük olduğu değerler anlamlı olarak kabul edildi.

\section{Bulgular}

Gruplar arasında yaş ve cinsiyet yönünden fark bulunmadı ( $\mathrm{p}>0,005)$. Ortalama 1.gün hemovaktaki kan miktarı Grup 1 'de $400 \mathrm{ml}( \pm 208,5), 2$.grupta $530 \mathrm{ml}( \pm 136,6)(\mathrm{p}=0,003)$, 2.gün hemovaktaki kan miktarı grup 1'de $150 \mathrm{ml}( \pm 45,2), 2$. Grupta $100 \mathrm{ml}( \pm 114,9)(\mathrm{p}=0,403)$ olarak belirlendi. Ortalama intraoperatif ve postoperatif transfüzyon ihtiyac1, preop ve postop hb değerleri, hastanede kalış süresi benzerdi $(\mathrm{p}>0,05)$. Her iki grupta da turnikeye bağlı bir komplikasyon gelişmedi, yeniden bir operasyonu gerektirecek hematom, enfeksiyon gibi bir komplikasyona rastlanmadı (Tablo 2).

\begin{tabular}{|c|c|c|c|}
\hline & $\begin{array}{c}\text { Grup1 } \\
(\mathrm{n}=37) \\
\text { Ortalama } \pm \mathrm{SD} \\
\text { Median }[\text { min-maks }]\end{array}$ & $\begin{array}{c}\text { Grup2 } \\
(\mathrm{n}=43) \\
\text { Ortalama } \pm \mathrm{SD} \\
\text { Median }[\text { min-maks] }\end{array}$ & $P$ de $\breve{\mathrm{g} e r i}$ \\
\hline $\begin{array}{l}\text { Preoperatif } \\
\text { hemoglobin } \\
(\mathrm{g} / \mathrm{dL})\end{array}$ & $\begin{array}{l}12,6 \pm 1,5 \\
13[10-16]\end{array}$ & $\begin{array}{l}12,7 \pm 1,3 \\
13[10-16]\end{array}$ & 0,547 \\
\hline $\begin{array}{l}\text { Postoperatif } \\
\text { hemoglobin } \\
(\mathrm{g} / \mathrm{dL})\end{array}$ & $\begin{array}{l}10,9 \pm 1,5 \\
11[9-15]\end{array}$ & $\begin{array}{l}11,3 \pm 1,2 \\
11[9-15]\end{array}$ & 0,096 \\
\hline $\begin{array}{c}\text { Taburcu } \\
\text { olduğu gün } \\
\text { hemoglobin } \\
\text { (g/dL) }\end{array}$ & $\begin{array}{l}10,5 \pm 1,2 \\
11[9-14]\end{array}$ & $\begin{array}{l}10,9 \pm 1,0 \\
11[9-14]\end{array}$ & 0,255 \\
\hline $\begin{array}{c}\text { 1.gün } \\
\text { hemovakdaki } \\
\text { kan miktarı } \\
(\mathrm{mL})\end{array}$ & $\begin{array}{l}383,7 \pm 208,5 \\
400[100-900]\end{array}$ & $\begin{array}{l}478,6 \pm 136,6 \\
530[250-800]\end{array}$ & 0,003 \\
\hline $\begin{array}{c}\text { 2. gün } \\
\text { hemovakdaki } \\
\text { kan miktari } \\
(\mathrm{mL})\end{array}$ & $\begin{array}{l}132,7 \pm 45,2 \\
150[50-200]\end{array}$ & $\begin{array}{l}149,3 \pm 114,9 \\
100[50-650]\end{array}$ & 0,403 \\
\hline $\begin{array}{c}\text { Íntraop kan } \\
\text { ihtiyacı (ünite) }\end{array}$ & $0,5 \pm 0,7$ & $\begin{array}{c}0,6 \pm 0,9 \\
0[0-3]\end{array}$ & 0,978 \\
\hline $\begin{array}{c}\text { Postop kan } \\
\text { ihtiyacı (ünite) }\end{array}$ & $0,4 \pm 0,8$ & $\begin{array}{c}0,9 \pm 1,1 \\
0[0-4]\end{array}$ & 0,078 \\
\hline $\begin{array}{l}\text { Yatış süresi } \\
\text { (gün) }\end{array}$ & $\begin{array}{l}10,4 \pm 2,0 \\
11[7-15]\end{array}$ & $\begin{array}{l}11,7 \pm 2,6 \\
11[7-21]\end{array}$ & 0,063 \\
\hline
\end{tabular}

\section{Tartışma}

Total diz artroplastisi uygulamalarında turnike sıklıkla kullanılmaktadır. Turnike kullanımının kanamayı azalttığı, operasyon süresince daha iyi görüş sağladığı ve sementlemeyi kolaylaştırdığı konusunda görüş birliği olmasına rağmen, turnike açılma zamanı ve kanama kontrolüyapılıpyapılmaması konusunda literatürde ortak bir görüş bulunmamaktadır. Turnike kullanımının, turnikenin açılma zamanı ve kanama kontrolü yapılmasının kan kaybı üzerine etkisini gösteren çeşitli çalışmalar (Pak ve ark., 2010) olmakla birlikte, turnike kullanılan ve kullanılmayan hastalarda kan kaybında 
bir fark olmadığını gösteren çalışmalar da mevcuttur. Salam ve ark. (1995) yaptıkları çalışmada turnike uyguladıkları grupta hemovak drenlere olan toplam kanama miktarın 800 $\mathrm{ml}$, turnike uygulamadıkları grupta $850 \mathrm{ml}$ ölçtüler. İki grup arasında anlamlı fark bulmadılar. Biz çalışmamızda 1. gün hemovakta toplanan kan miktarının kanama kontrolü yapılan grupta, kanama kontrolü yapılmayan gruba kıyasla daha az olduğunu gördük $(p=0,003)$. Gruplar arasında intraoperatif ve postoperatif kan transfüzyon ihtiyacında anlamlı farklılık bulamadik.

Total diz artroplastisi sonrası derin ven trombozu gelişimi hastalar için pulmoner emboli yönünden önemli bir risk faktörüdür. Turnike kullanımının total diz artroplastisinde derin ven trombozu (DVT) gelişimini artırmadığını öne süren çalışmalar vardır. Hasegawa ve ark. (2007) yaptıkları çalışmada, hastaları rastgele 2 gruba ayırdıktan sonra; ilk gruba turnike eşliğinde, ikinci gruba turnike uygulamadan total diz artroplastisi uyguladilar. Postoperatif tüm hastalar ultrasonografi ile DVT açısından görüntülendi. Çalışmaya katılan tüm hastalarda postoperatif DVT gelişme riskini \% 81,3, semptomatik pulmoner emboli gelişme riskini \% 1,7 olarak buldular. İki grup arasında DVT gelişim açısından anlamlı fark bulamadılar. Bizim çalışmamızda her iki grupta da postoperatif semptomatik pulmoner emboli görülmedi. Sementli ve sementsiz protez uygulamalarına bakıldığında; sementsiz uygulamalarda kan kaybının daha fazla olduğu görülmekte, sementin mekanik, kimyasal ve termal özellikleri ile kanamayı azalttığı düşünülmektedir (Christodoulou ve ark., 2004). Çalışmamızda tüm hastalarda sementli protez kullandık. Turnike erken açılan grupla geç açılan grubu karşılaştırıldığında; yara kapandıktan sonra turnike açılan grupta ek cerrahi girişim gerektirebilecek hematom, yara yeri enfeksiyonu, hareket kısıtlılığı gibi erken dönem postoperatif komplikasyonların daha yüksek olduğunu belirten çalışmalar mevcuttur (Rama ve ark., 2007). Bizim çalışmamızda hiçbir hastamızda ek cerrahi gerektirebilecek komplikasyona rastlanmadi.

Total diz protezi (TDP) de kanamayı etkileyen bir diğer faktör, uygulanan postoperatif rehabilitasyon programıdır. Turnike açılma zamanı ve sürekli pasif hareket (CPM) cihazı kullanımının kan kaybına etkisini gösteren bir çalışmada; (Lotke ve ark., 1991) hastaları iki gruba ayırdıktan sonra, 1. gruptaki hastalarda turnikenin intraoperatif açılıp kanama kontrolü yapılmış ve postoperatif hemen CPM cihazı kullanılmaya başlanmış, 2. grupta ise turnike intraoperatif açılıp kanama kontrolü yapıldıktan sonra CPM, 3. gün kullanılmaya başlanmıştır. Veriler incelendiğinde 2. grupta daha az kanama olduğunu görmüşler ve bu yüzden CPM'nin kanamayı artırdığını belirtmişler. Çalışmamızda her iki gruba da aynı rehabilitasyon programını uyguladık, hiçbir hastamızda CPM cihazı kullanmadık. Intraoperatif kanama kontrolü yapılması major damar yaralanmasının saptanması yönünden önemlidir fakat total diz artroplastisi esnasında major damar yaralanması oldukça nadir görülmektedir (Lotke ve ark., 1991). Turnike açılmasını takiben dorsalis pedis ve tibialis posterior nabızlarını palpe etmek major damar yaralanmasını tespit etmede pratik bir yoldur. Sonuç olarak; turnikenin erken açılması postoperatif hemovak drene olan kan kaybını azaltmasına rağmen hastaların transfüzyon ihtiyacında değişikliğe yol açmamaktadır. Biz turnikenin erken açılıp kanama kontrolü yapılmasının klinik olarak önemli olduğunu düşünmekteyiz.

\section{KAYNAKLAR}

Burkart, B.C., Bourne, R.B., Rorabeck, C.H., Kirk, P.G., Nott, L., 1994. The efficacy of tourniquet release in blood conservation after total knee arthroplasty. Clin. Orthop. 299, 147-152.

Christodoulou, A.G., Ploumis, A.L., 2004. The role of timing of tourniquet release and cementing on perioperative blood loss in total knee replacement. Knee. 11, 313-317.

Hasegawa, M., Kato, K., Shi, D., Sudo, A., Uchida, A., 2007. Effect of tourniquet application on deep vein thrombosis after total knee arthroplasty. Arch. Orthop. Trauma Surg. 127, 671-675.

Hersekli, M.A., Akpınar, S., Ozkoc, G., Ozalay, M., Uysal, M., Cesur, N., 2004. The timing of tourniquet release and its influance on blood loss after total knee artroplasty. Int. Orthop. 28, 138-141.

Jorn, L.P., Lindstrand, A., Toksvig-Larsen, S., 1979. Tourniquet release for hemostasis increases bleeding. A randomized study of 77 knee replacements. Acta Orthop. Scand. 70, 265-267.

Lotke, P.A., Faralli, V.J., Orenstein, E.M., Ecker, M.L., 1991. Blood loss after total knee replacement: Effects of tourniquet release and continuous passive motion. J. Bone Joint. Surg. Am. 73, 1037-1040.

Newman, J.H., Jackson, J.P., Waugh W., 1979. Timing of tourniquet removal after knee replacement. J. Roy. Soc. Med 72 , $492-494$.

Page, M.H., Shepard, B.D., Harrison, J.M., 1994. Reduction of blood loss in knee arthroplasty. Aust. N. Z. J. Surg. 54, $141-144$.

Pak, J., 2010. Biol. Sci. 13, 249-252.

Rama, K.R., Apsingi, S., 2007. Timing of tourniquet release in knee arthroplasty. Meta-analysis of randomized, controlled trials. J. Bone Joint Surg. Am. 89, 699-705.

Salam, A.A., Eyres, K.S., 1995. Effects of tourniquet during total knee arthroplasty. J. Bone and Joint Surg. Br. 77, $250-253$. 